Article

\title{
Can a University Campus Work as a Public Space in the Metropolis of a Developing Country? The Case of Ain-Shams University, Cairo, Egypt
}

\author{
Mona $\mathrm{Ali}^{1}$ and Youngmin Kim ${ }^{2, *}$ \\ 1 Housing and Building National Research Center, 87 El-Tahrir ST., Dokki, Giza 11511, Egypt; \\ monatalaat.13@hotmail.com \\ 2 Department of Landscape Architecture, University of Seoul, 163 Seoulsiripdaero, Dongdaemun-gu, \\ Seoul 02504, Korea \\ * Correspondence: ymkim@uos.ac.kr
}

Received: 15 July 2020; Accepted: 29 August 2020; Published: 3 September 2020

\begin{abstract}
Even though public open space has been taking more important roles in improving urban environments, most of the metropolises in developing countries suffer from lack of both quantity and quality of parks and green spaces. This research examined the possibility of opening the university campus to the public in order to improve the public space service of the city, focusing on the case of the Ain-Sham University campus in Cairo, Egypt. The study is structured in three steps: (1) Analysis of open space distribution at the district level to find out how the university campus can contribute to improving urban public service, and if it works as an open space; (2) Survey of resident and student groups to find a perception of opening the campus for public use; and (3) Interview with government officials and university faculty members. The level of agreement on opening the campus was neutral from both resident and student groups. However, the result shows some significant acceptance of opening specific places for public use upon employing proper strategies. According to the result, it is not appropriate to fully open the controlled public space of universities in the context of Cairo, following exemplary cases of developed countries. Although sharing privatized open space with adjacent communities can be a good solution for the fast-growing metropolis, lack of proper public spaces, and insufficient resources, the process should be carefully designed with step-by-step implementation strategies.
\end{abstract}

Keywords: Greater Cairo; public spaces; public space management; open campus plan; university-community relationship

\section{Introduction}

Open spaces are no longer luxuries but are indispensable amenities to create a more sustainable society [1]. The UN established specific targets for SDG (Sustainable Development Goals) 11, to make cities and human settlements inclusive, safe, resilient and sustainable [2]. One of its targets is to provide universal access to green and public spaces, in particular, for women and children, older persons, and persons with disabilities [3]. Many developed countries were able to successfully improve their green and public space qualities and accessibilities in past decades; whereas, in developing countries, the high financial cost and scarcity of proper lands remained the chief obstacles in creating better public open spaces. Faced with challenges in improving green and public spaces in developing countries, more flexible design approaches and policies became necessary to maximize the utilization of existing resources. According to the UN-Habitat (2015), "Public open space does not include the areas devoted to public facilities-e.g., schools, stadiums, hospitals, airports, waterworks, or military bases-that are not open to the general public" [4] (p. 2). However, these non-public open spaces associated with 
public facilities can provide opportunities to revitalize communities, especially when a municipality does not have enough resources to secure public open spaces. Recently, many scholars and policy makers have paid special attention to integrating university campuses to the existing urban fabrics in order to provide better open space service through institutional partnership without spending public funds.

This research explores the possibility of sharing spaces of the university campus with the public in Greater Cairo (GC), Egypt-a case representing high-density urban areas in developing countries confronting multiple urgent urban problems requiring immediate actions. Even though there are many successful cases sharing university facilities and amenities with neighborhoods in the U.S. and Europe, the research assumes that the Cairene perception about sharing institutional spaces can be different from that of the Western world due to different cultural and social backgrounds. The goal of the research is as follows: (1) To examine the general perception of university community and adjacent neighborhoods about sharing various campus spaces; and (2) to find out realistic solutions to improve city-wide public space service by establishing a partnership between the university and the city based on the survey and the in-depth interviews. The research primarily focused on the open space amenity of the university, which can be easily shared with citizens without additional investment; however, it does not limit the amenities to open spaces, also exploring the possibility to open other university facilities to the public. In terms of terminology, the research regards public space as the concept including both public open spaces and public facilities such as libraries, classrooms, and sports facilities. The privatized public space in the research refers to both open spaces and facilities owned and managed by the private sector, which requires a specific fee to enter or use them, which is typical in Cairo. The semi-public space means that both open spaces and facilities are owned and managed by the municipality but dedicated to specific users with a specific fee.

\subsection{The Urban Landscape of Cairo}

The Cairene landscape has been affected by its multicultural history in addition to climatic, political, and religious factors, resulting in high density and a compact urban form. In medieval Cairo, public open spaces were dedicated to business, military, and religious uses [5]. Some private outdoor spaces were opened to the public during special occasions, such as festivals and royal weddings [6]. By 1867 , several infrastructure projects established a foundation of the modern metropolis with the construction of modernized streets, squares, gardens, railroads, water network, stabilization of the riverbanks, and draining of seasonal ponds [6,7]. The urban situation of Cairo changed under the pressure of constant urban population growth. In the 1970s and 1980s, rapid growth of urban areas increased unplanned settlements, which occupied a large amount of agricultural lands adjacent to the city, causing undesirable impacts such as insufficient infrastructure, urban service deterioration, and slum growth [6]. During the 1980s and 1990s, many public open spaces were swept by high-end commercial establishments like hotels, clubs, and restaurants [5]. Due to the high cost of developing desert areas, high land value of open spaces in the city, and tendency to pursue short-term revenue, the market took over urban open spaces for new developments [5-8]. As a result, open spaces decreased, significantly deteriorating living conditions in the inner city during this period. Nowadays, most of the new residential developments are gated communities seeking isolation from the surrounding low-quality urban environment [9].

UN-Habitat defines public spaces as "all places publicly owned or of public use, accessible, and enjoyable by all for free and without a profit motive" [10] (p. 6). Not much different from the situation of many developing countries, most of the public open spaces are in poor quality, failing to attract diverse social user groups in Egypt [11]. As an attempt to improve the quality of public open spaces, the Egyptian government started to require a membership or a small entrance fee to use open spaces. However, the upper- and middle-income residents prefer privatized open spaces, looking for better amenities with a diversity of programs [8]. Moore criticized such tendency of increasing exclusive open spaces: "You have to pay for the public life" [12]. Developed countries can easily invest in public 
parks to create a more sustainable urban environment, while developing countries usually give a low priority to building or improving their public open spaces compared to other projects. The World Health Organization (WHO) (2012) states that the minimum standard of the green space shares per capita should be $9 \mathrm{~m}^{2}$ within $15 \mathrm{~min}$ of walking distance from home [13] (Figure 1). According to the GOPP et al. (2012), green space shares per capita in GC Metropolitan Region is $3 \mathrm{~m}^{2}$ [14]. The National Organization for Urban Harmony (NOUH) (2010) puts a target to increase open and green space shares per capita and to reach $7 \mathrm{~m}^{2}$ in the Nile basin area and $5 \mathrm{~m}^{2}$ in deserted areas as a minimum requirement for the existing cities [15] (Table 1). However, green space in the GC area barely changes, maintaining the status of $3 \mathrm{~m}^{2}$ per capita, which is far below the standard of WHO.

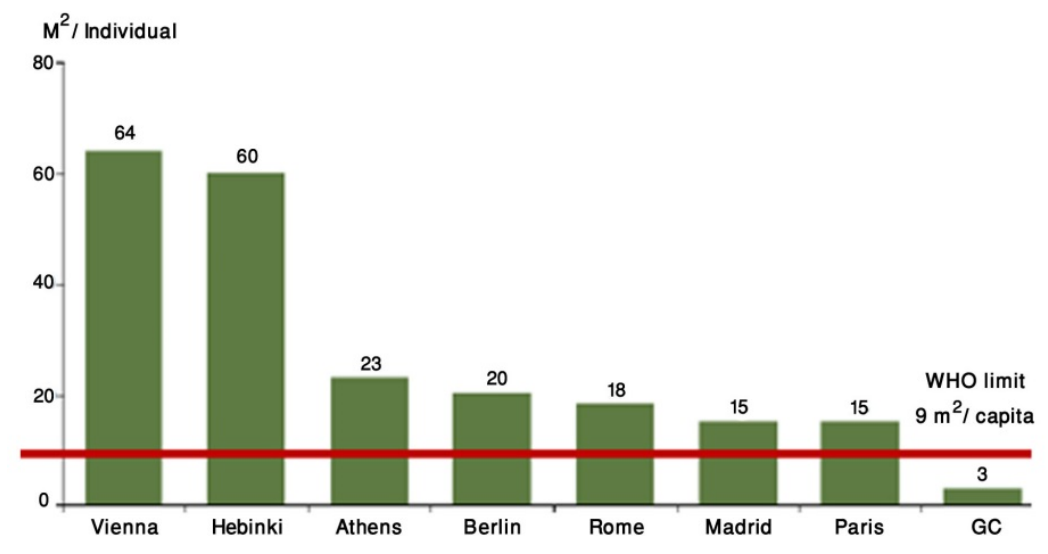

Figure 1. Per capita share of green space of various cities [14].

Table 1. Norms of public spaces in Egypt [15].

\begin{tabular}{ccccccc}
\hline & \multicolumn{2}{c}{ Nile Basin } & \multicolumn{2}{c}{ Deserted Areas } & \multirow{2}{*}{ Current Situation } \\
\cline { 2 - 5 } & Minimum & Target & Minimum & Target & \\
\hline Existing Cites & 7 & 10 & 5 & 7 & $0.5-1.5$ \\
\hline New Cities & 15 & 20 & 10 & 15 & $7-13$ \\
\hline
\end{tabular}

According to NOUH (2010), the semi-public spaces, dedicated to specific users, such as social and sports clubs, school sports fields, or youth centers, could be regarded as public spaces only if they are less than half of the total area of the public spaces [15]. Public open spaces at the district level should be within $15 \mathrm{~min}$ or $1000 \mathrm{~m}$ walking distance from home, with an area of 3 feddan and at least one being 5 feddan $\left(1\right.$ feddan $\left.=4200 \mathrm{~m}^{2}\right)$ [15]. Public open spaces in the neighborhood-level should be within $400 \mathrm{~m}$ walking distance from home [15]. According to Saikia, in order to ensure the proper use of parks, "it is very important that the parks are located in places where they are needed the most" [16]. Talen (2010) stated three normative principles related to the spatial distribution of parks: "proximity, diversity, and social need" [17]. Cairo needs to improve the spatial distribution of public open spaces; however, it is hard to find proper solutions because of limited funding and lack of effective strategies for implementation.

\subsection{A New Paradigm Shift Towards an Open-University Campus}

According to recent researches and case studies, university campuses shared with the public can provide multiple positive effects to the city, revitalizing adjacent communities, creating more job opportunities, enhancing ecological services and providing safe and sociable public gathering places. Even though the first universities were products of medieval Europe around the 11th century, the first university campuses appeared in Oxford and Cambridge around the 17th century [18]. Their designs were influenced by the cloistered monastery, an arrangement of typically enclosed buildings in an 
introverted design promoting isolation from the outside environment. By the 1770s, the term "campus" was first used to describe the entire ground of Princeton University where the college was located in a building along one side of green space [19].

Grumprecht (2007) regards that the park-like model of the university campus is largely an American invention [18]. It was landscape architects such as Frederick Law Olmsted who established the foundation for university campuses as a park-like setting in the late 19th and the early 20th century. Olmsted's intention for the campus design was not much different than that for the public parks, promoting the physical and mental health of users [20]. The American model of the university campus was typically located in a rural environment to be separated from the disorder of the urban context [19]. This model was exported to Europe, Latin America and Asia to be the international standard for university master planning in the last century.

However, Haar (2011) noted that the paradigm shift for university campus planning has been witnessed form the late 20th century [21]. Universities have been trying to expand their campus toward the city, merging boundaries with adjacent neighborhoods. The Massachusetts Institute of Technology's (MIT) campus expansion around Kendall Square, Harvard University's new Allston campus, and the University of Chicago's expansion cooperating with surrounding communities are good examples of "the campus integrated with the city" model. This alternative model was applied in many university new master planning projects in the 21st century. The University of Pennsylvania's strategic masterplan, "Penn Connects," expanded university properties to neighborhoods enlarging public open spaces of the city [22]. The University of Washington recently completed "2018 Campus Master Plan (CMP)," mixing the campus facilities with adjacent urban fabrics [23]. In the U.K., the University of Cambridge is leading the development of Cambridge through the "North West Cambridge Development Masterplan [24]." (see Figures 2 and 3)

The new relationship between university and city has been largely discussed in the academia as well as in the field of practice [25-34]. Rashidi (2013) classified the integration between university and city into a physical, socio-culture, and economic relationship [25]. Fassi, Galluzzo and Rogel (2016) searched the possibility to open the Milano Bovisa Durando campus to the public. Their research found that residents considered campus boundaries with gates as a restricted barrier, making it hard for them to access the university campus [26]. Dalton et al. (2018) reviewed recent methods of campus planning [27]. They organized campus planning trends into three scales: the campus park, the campus-community interface, and the larger campus district. Their findings show that many of the current campus master planning projects do not limit their boundary to the traditional campus area but expand to the larger city context. Herbert (2018) examined a recent shift in the university campus planning and design, expanding its territories to the various contexts of the city [28]. He analyzed the principal lines of campus design into three topics: campus in context, estate layout, and mixing of uses. Way (2018) examined the new master planning approach of the University of Washington as a case study. She concluded that "it suggests an alternative approach to how the academy engages the city and its productive potential" through the campus design as a good urban design [29].

If the researches mentioned above focused on the physical planning of the campus, there are also literatures which examined a flexible governance structure and an open partnership between the university and the public. Bringle and Hatcher (2002) redefined campus-community partnerships through the concept of service-learning. In order to develop healthy partnerships, they structured the phases of relationships as initiation, development, maintenance, and dissolution; and the dynamics of relationships as exchanges, equity, and distribution of power [30]. Martin et al. (2005) examined the innovative partnership structure for universities to work cooperatively to address shared issues. They identified seven taxonomies for a successful, innovative university and community partnership: service-learning, service provision, faculty involvement, student volunteerism, community in the classroom, applied research, and institutional change [31]. Burning et al. (2006) tried to broaden the definition of community engagement of universities through the research. The results showed that community members who participated in a campus event more actively showed favorable 
responses to the university [32]. McHugh and Meister (2004) introduced successful models for strategic campus facility planning through the campus-public partnership and through the case study of DePaul University in Chicago [33]. Porter (2007) points out how university campuses can serve as socio-cultural hubs hosting and sponsoring diverse community activities. Universities can enhance the local economy through various initiatives, ranging from "providing jobs and developing real estate to offering advice to startups and conducting basic research that catalyzes and supports local industries" [34].

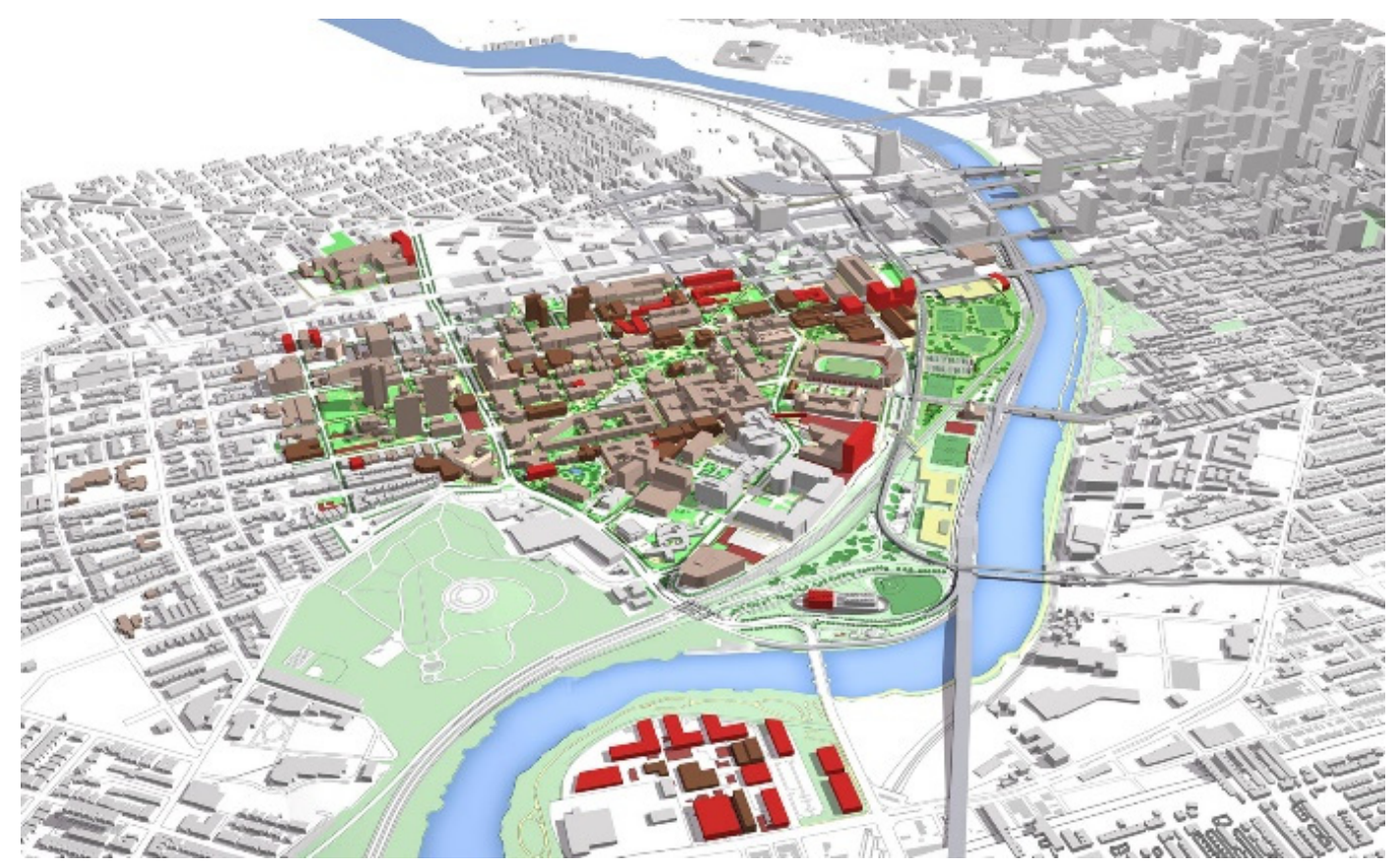

Figure 2. Penn Connects, 2011 [22].

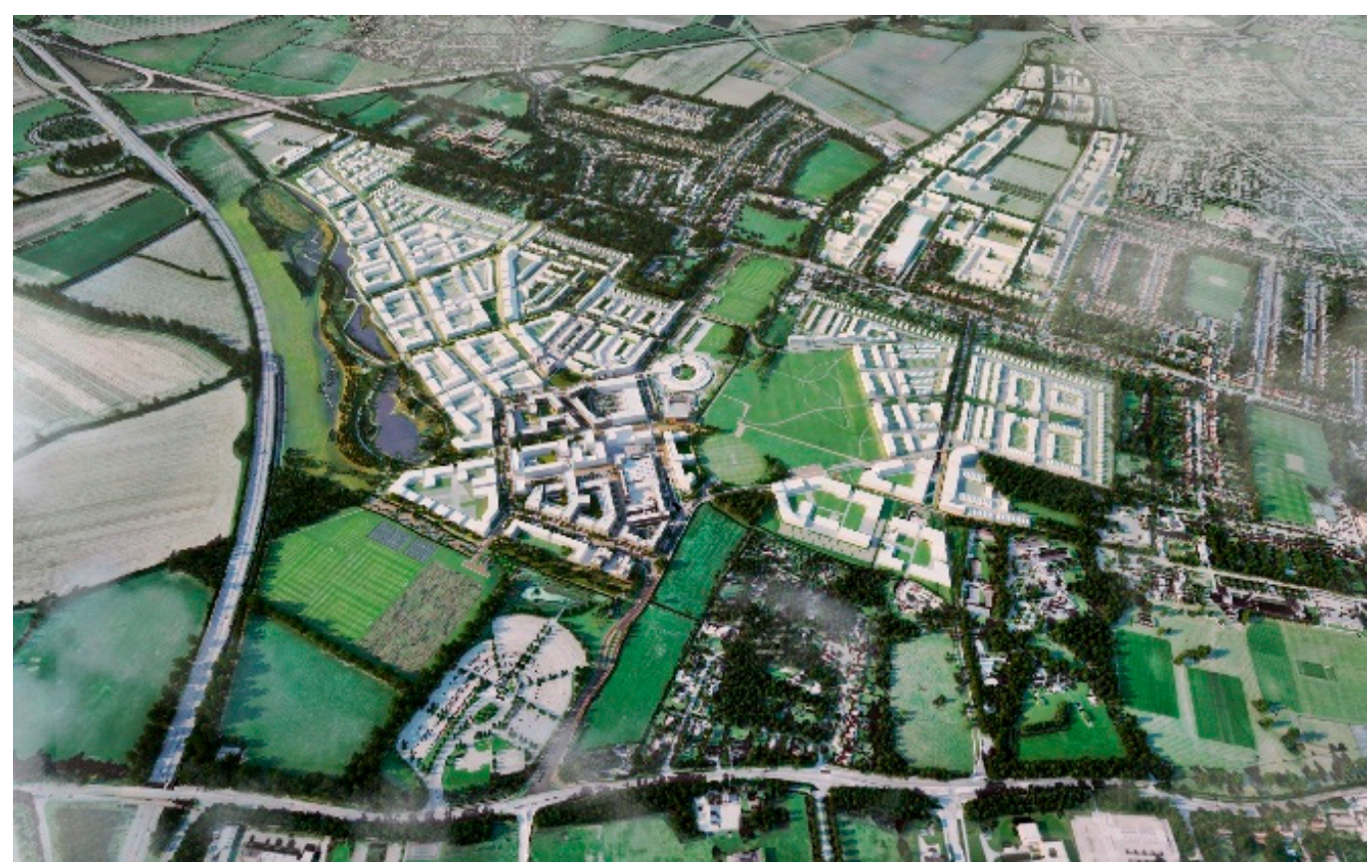

Figure 3. North West Cambridge Masterplan, 2013 [24]. 
Even though many recent literatures encourage to integrate the campus with the city and share amenities with surrounding neighborhoods through healthy campus-community partnerships, it should be noted that those literatures are mostly based on the cases of the U.S. and Europe. Planning strategies and policies proven to be successful in the Western world frequently fail in developing countries due to different economic status and social context. In addition, Cairo has a different climate and culture from most of the cases introduced in the literatures. Therefore, delicate approaches and on-site field studies are required when trying to change the existing pattern of spatial use.

\section{Materials and Methods}

\subsection{Study Context}

The study focuses on the Ain-Shams University (ASU), one of the public universities in GC, and El-Waily District (EWD), the district where the four campuses of ASU are located. The GC region includes three governorates: Cairo, Giza, and Qalioubiya. EWD, which consists of two departments, El-Waily and El-Zaher, is located in the western area of the Cairo governorate. The study area is selected by the following three criteria. The first criterion is the high demand for public open spaces in the district level. Universities located in the district with plenty of open spaces are excluded. The second criterion is high population density in the low-income level group or among people who do not have an easy access to privatized open spaces. The third criterion is the availability of open and green spaces within the university, which can potentially work as a park if the campus is opened to the public. The selection criteria were based on the UN's SDGs' indicators, especially five indexes to evaluate SDG 11.7, which is about providing universal access to green and public spaces [3]. Several literatures about park service and planning criteria were also referred [35-38]. Among 24 universities in GC, four universities, Cairo, Helwan, Al-Azhar, Ain-Shams, were selected as candidates based on the criteria, and ASU was selected considering detailed conditions.

\subsection{Context of ASU Campus/Spatial Structure of ASU Campus with Campus Maps}

ASU, founded in 1950, is the third oldest university in Egypt after Cairo University and Alexandria University. The main campus was originally the Zaafaran Palaces built during the regime of Khedive Ismail. In 1950, ASU started with 8 faculties. The Faculty of Education was added in 1969 and the Faculty of Al-Alsun in 1973. At present, ASU comprises 7 campuses in GC with 15 faculties and 2 high institutes. The focus of this study includes the main campus and the fourth campus of El-Waily for the Faculty of Engineering (FOE). The two other campuses, which have major medical facilities, are not included in the study since it is not proper to open them to the public for security issues. The main campus includes the administration building, Faculties of Arts, Law, and Science, and Faculty of Computer and Information Sciences. There are large green spaces with a boulevard in the middle of the campus. The main campus is completely enclosed with a solid wall and formal gates except for the iconic gate. The fourth campus includes the Faculty of Engineering founded in 1839. Recently, the campus has gone through major renovations introducing new buildings with several open courtyards and a sports field. Not much different from the main campus, the FOE campus is surrounded by formal gates and with metal fences. (see Figures 4-8) 


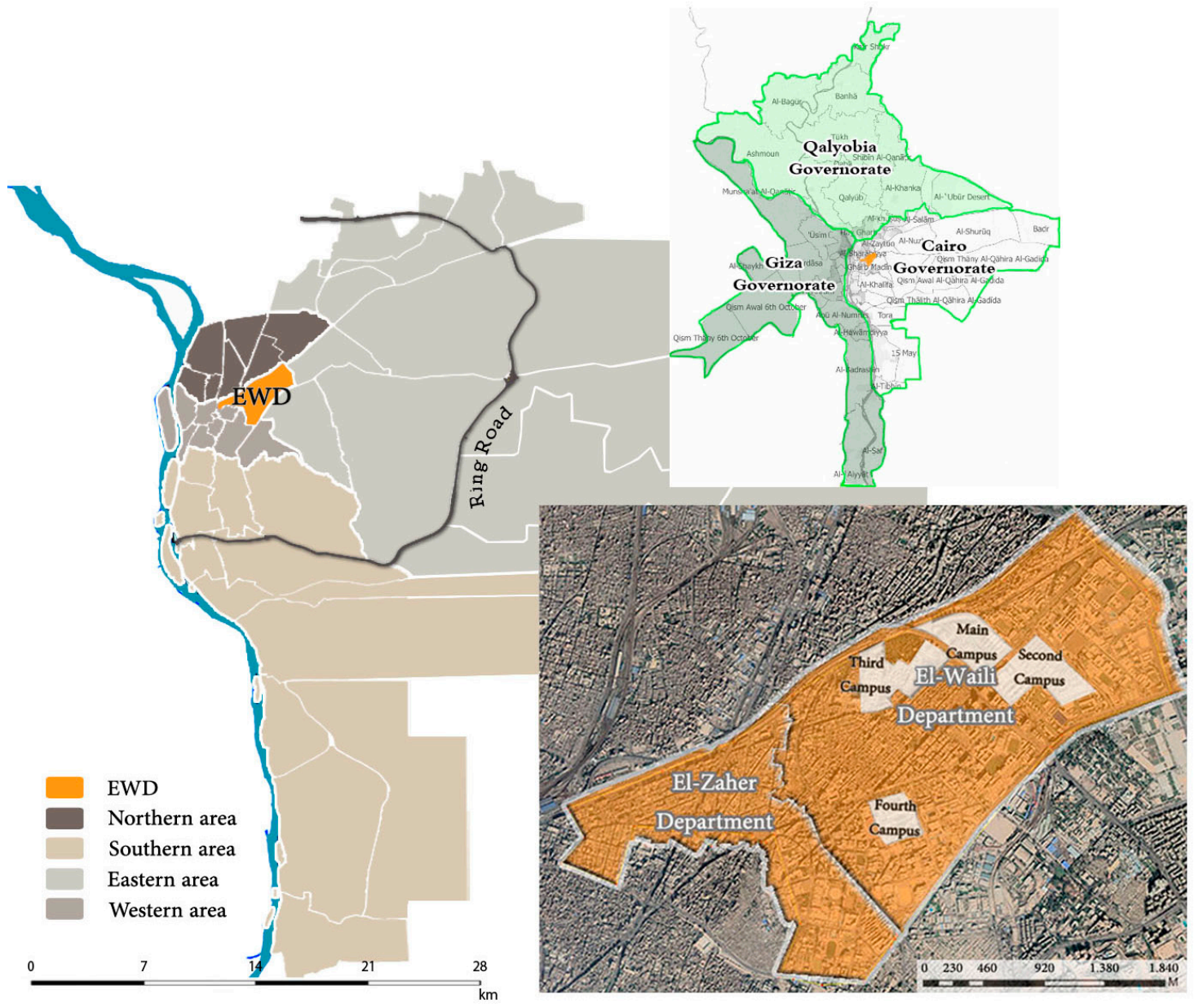

Figure 4. EWD in the GC area and ASU campuses' location in EWD [39], edited by the researcher.

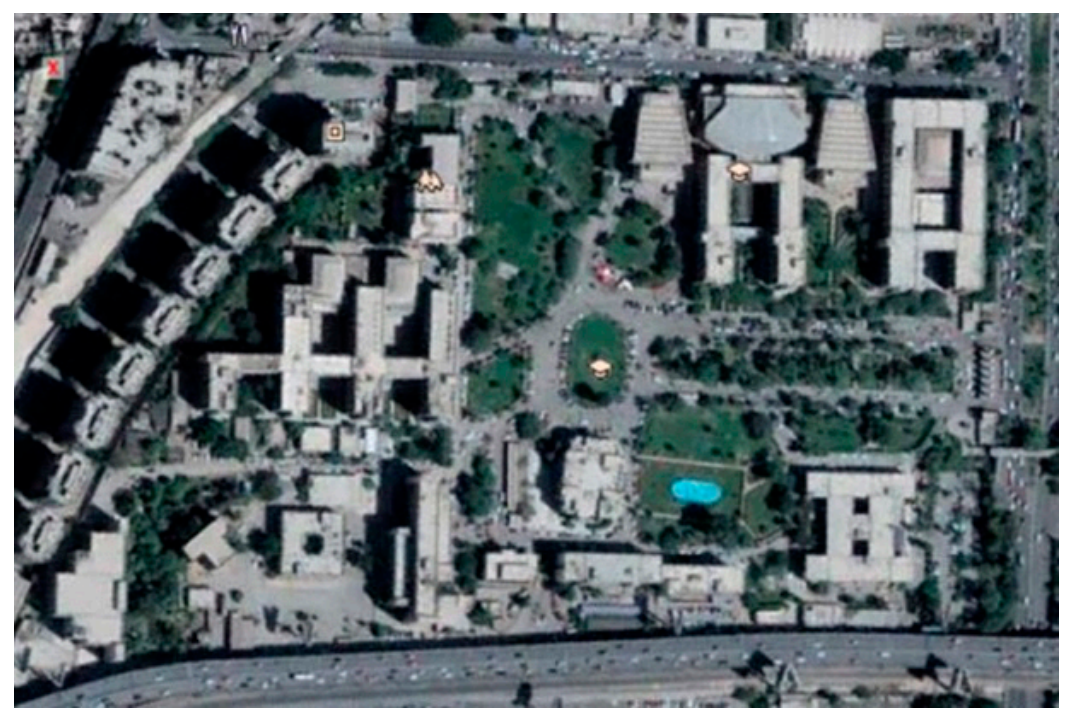

Figure 5. ASU layout [40]. 


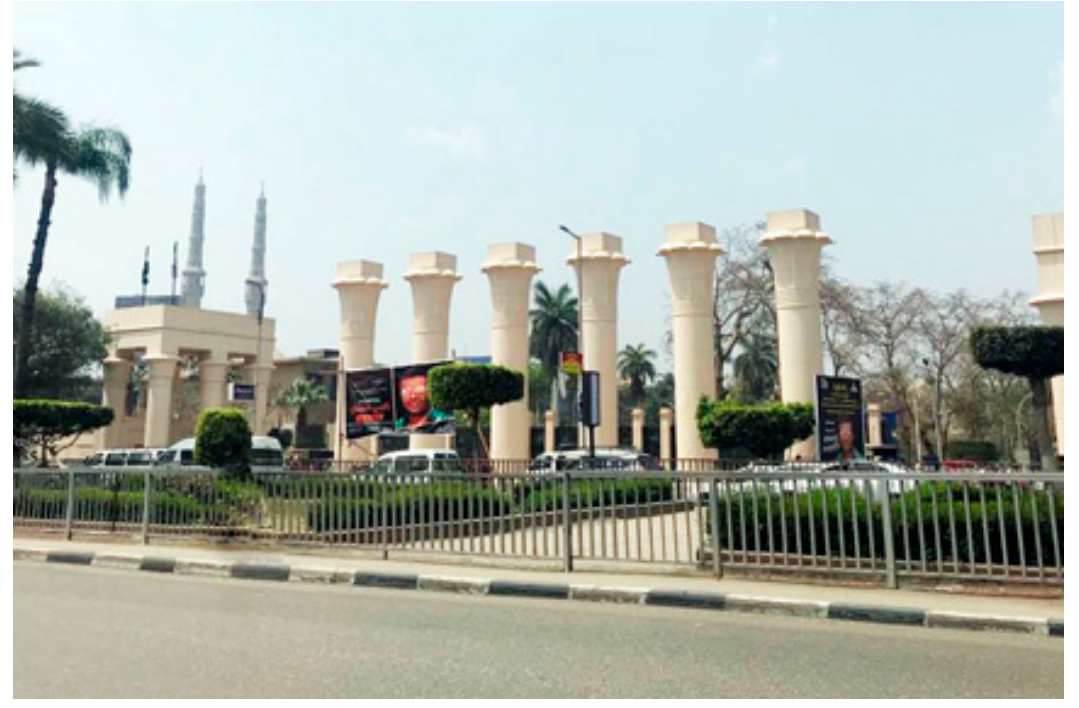

Figure 6. ASU Main Gate, taken by the researcher.

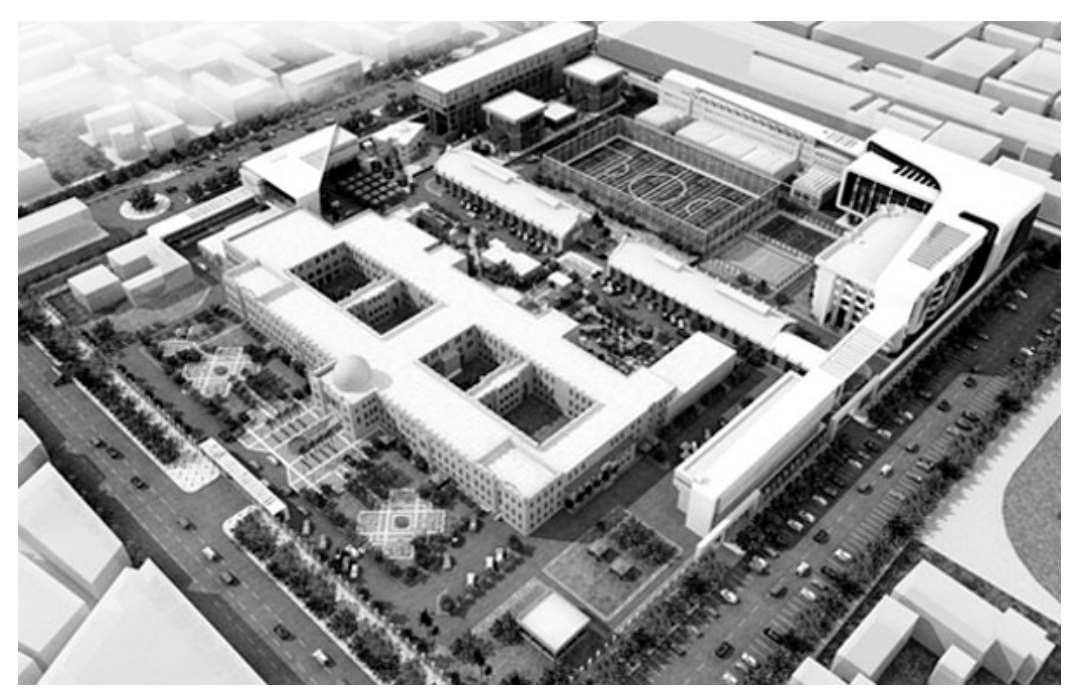

Figure 7. FOE Campus [41].

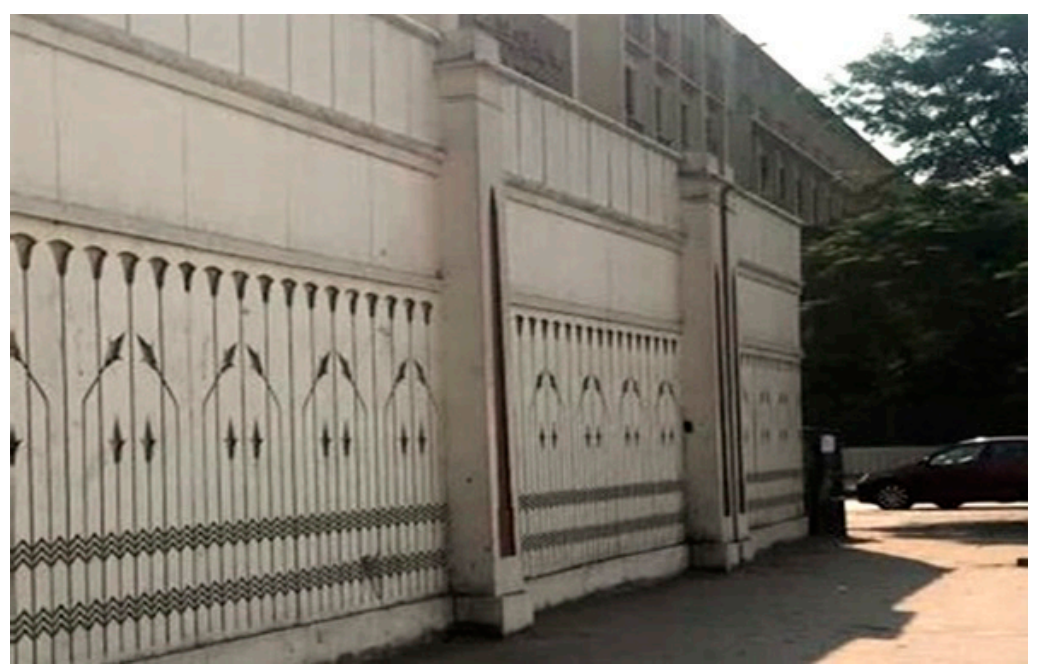

Figure 8. ASU solid fence, taken by the researcher. 


\subsection{Methodological Design Flow}

The main research question of this study is whether ASU can work as a public space or not. The main question leads to the secondary questions related with implementation, as well as with planning strategies, public policies, and partnerships between the university and the community. The research is based on the field survey and interviews; however, its main goal is to contribute in searching practical solutions for the given urban problem rather than finding the academic model to explain a specific social phenomenon. The research follows three steps as shown in Figure 9.

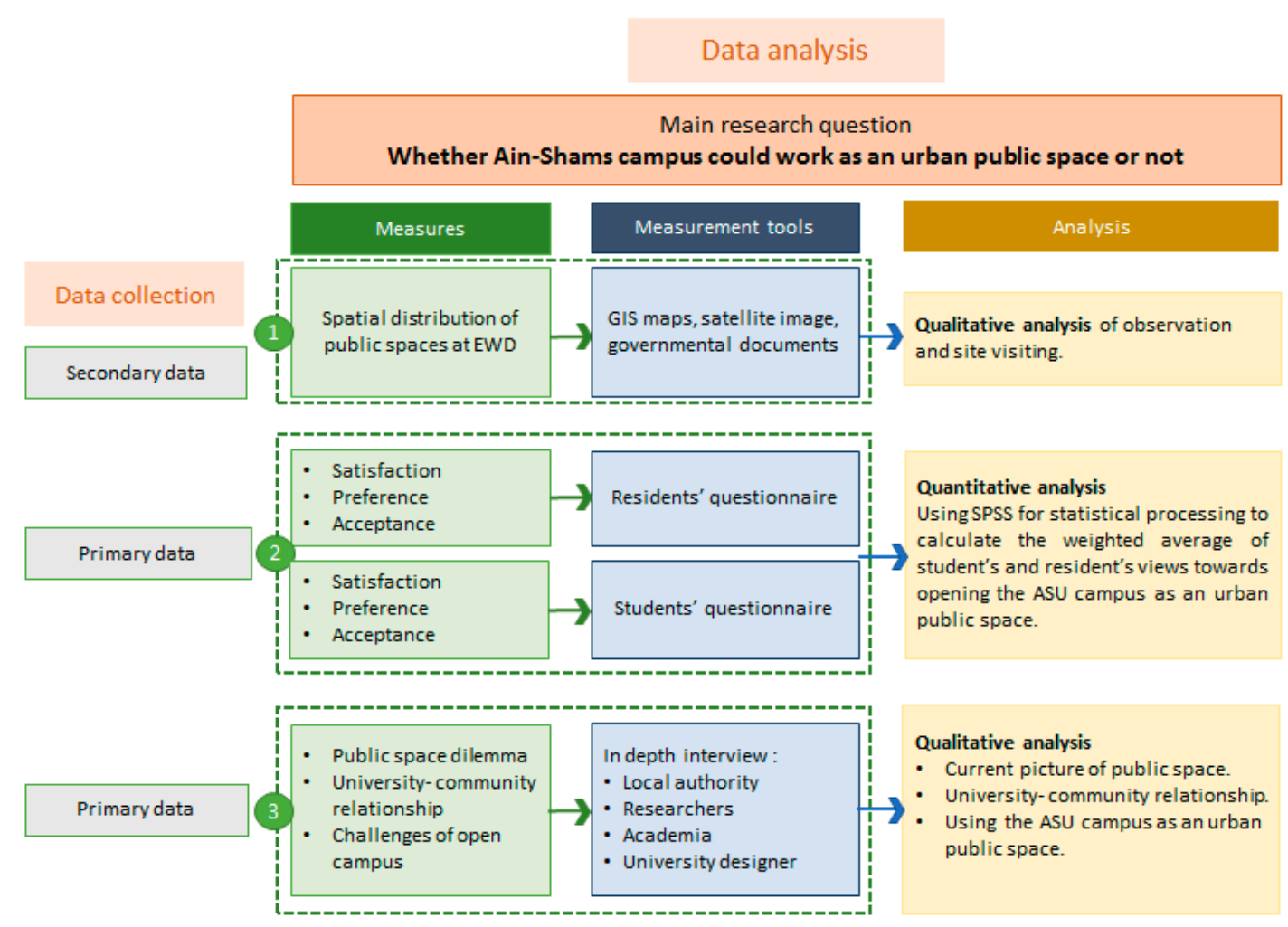

Figure 9. Research structure.

\subsubsection{Step 1-Analysis of Open Space Distribution at EWD}

The purpose of step 1 is to estimate the effects of sharing the campus with communities and to show how this alternative can improve the public open space service of the district. Since step 1 is the preliminary stage to provide grounds for the following two steps, the quantitative spatial analysis was not executed. In step 1, the study analyzed the spatial distribution of open spaces in EWD based on the survey and GIS data. Three types of open spaces were identified in the study. Type 1 is the public open space opened to the general public. Type 2 is the semi-public space opened to specific groups. Type 3 is open spaces of public institutions, such as universities or government offices, generally not opened to the public. The study examines how much area each open space can cover. The $1000 \mathrm{~m}$ radius areas for the district level service and the $400 \mathrm{~m}$ radius areas for the neighborhood- level service are investigated based on the literature reviews [15]. The study tries to find out how campuses of ASU can contribute to improving the public space services of the district if they are opened to the public.

\subsubsection{Step 2-Analysis of Opinions of Residents and Students}

The sample consists of two groups: the residents of EWD and the students of ASU. Convenience sampling is used for the sampling procedure. Convenience sampling is one type of non-random sampling, where the researcher selects the available and accessible participants at the 
time of conducting the survey. The participants were restricted to those at the selected sites, ASU and EWD. The questionnaires were first drafted in the English language then translated into Arabic. A pilot test was conducted by sending the Arabic version of each questionnaire to three reviewers. It took two months for designing, translating, and testing the questionnaires before reaching the final versions and distributing them. The two questionnaires were conducted on-site three times in January 2019. In addition, they were distributed among the social network of the researcher, targeting students of ASU or residents of EWD. To reach more of the population, some public pages and groups targeting the selected sites were used for distribution. In addition, a snowballing technique was adopted by request from some of the samples to publicize the questionnaire to others.

First group (residents of EWD): Sample $=63$, Sample universe $=153,986$ residents.

Second group (students of ASU): Sample $=81$, Sample universe $=168,970$ students.

SPSS is used for statistical analysis to calculate the weighted average of the answers to the questions. The questions are structured to find out the different opinions of residents and students on using ASU campuses as a public open space. Each questionnaire starts with fact-based questions followed by opinion-based questions structured in four parts: demographic information, satisfaction with the open spaces, preference, and the level of accepting the campus as a public open space. Most of the questions are evaluated by a five-point Likert scale, ranging from strongly disagree to strongly agree. The fourth section includes the same questions for each group concerning their perception of opening the ASU campus as a public space. Some questions were designed as multiple choices.

\subsubsection{Step 3-In-Depth Face-to-Face Interviews}

The study examines the rationale behind agreeing or disagreeing on opening the campus as a public open space through semi-structured interviews using open-ended questions. The interview was conducted to verify potentials and realistic obstacles in using the ASU campus as an urban public space in a more detailed level which the survey cannot reveal. The interview targeted key members of the university who could influence the policy of opening the campus to the public, including EWD local authority representatives, professors of the urban planning department at ASU, researchers from the regional research center, and representatives of a university design consultant. Questions are directed to obtain an extended vision of the public space dilemma in GC and to explore the relationship between the university and surrounding communities in GC.

\section{Results}

\subsection{Step 1-Analysis of Open Space Distribution at EWD}

The study examines the spatial distribution and proximity of open spaces at EWD. Open spaces, including the university campus, are categorized into three groups. If open spaces are not fully open to the public, it cannot be classified as a public open space. However, considering the context of Cairo, semi-public open spaces with a membership or small fee should be included in the public open space category. In Figure 10, Type 1 with dark green color is public open spaces fully opened to the general public. The light green color refers to Type 2 that serves only specific social groups. Type 2 includes open spaces of El-Nour Mosque, El-Wehda Mosque, St. Mark's Coptic Orthodox Cathedral and the Club of St. Ruiz. The campus of ASU is classified as the third type in Figure 10. The larger circles indicate district-level service zones of open space which are the areas within $1000 \mathrm{~m}$ walking distance from a designated open space. The smaller circles indicate neighborhood-level service zones of open space which are the areas within $400 \mathrm{~m}$ walking distance from a designated open space. The study shows that the western part of the El-Zaher department and the northeastern part of El-Waily department lack public open space services. Most of the open spaces, which are privately operated and which require additional conditions to use them, fall within $1000 \mathrm{~m}$ walking distance of the Type 1 open spaces. Opening ASU campuses to the public can significantly improve the neighborhood-level service of public space with proximity within $400 \mathrm{~m}$. Figure 11 shows the land use of EWD. The campus is 
located on main roads and easily accessed from metro stations. The residential area is concentrated at the center and the southwestern part of the district, near the campuses. If amenities of ASU campuses can be shared with the neighborhood, the accessibility to open spaces is expected to improve greatly. Opening cultural facilities, such as a theater, sports facilities, and libraries can provide public services to communities, which are not available in the district level.

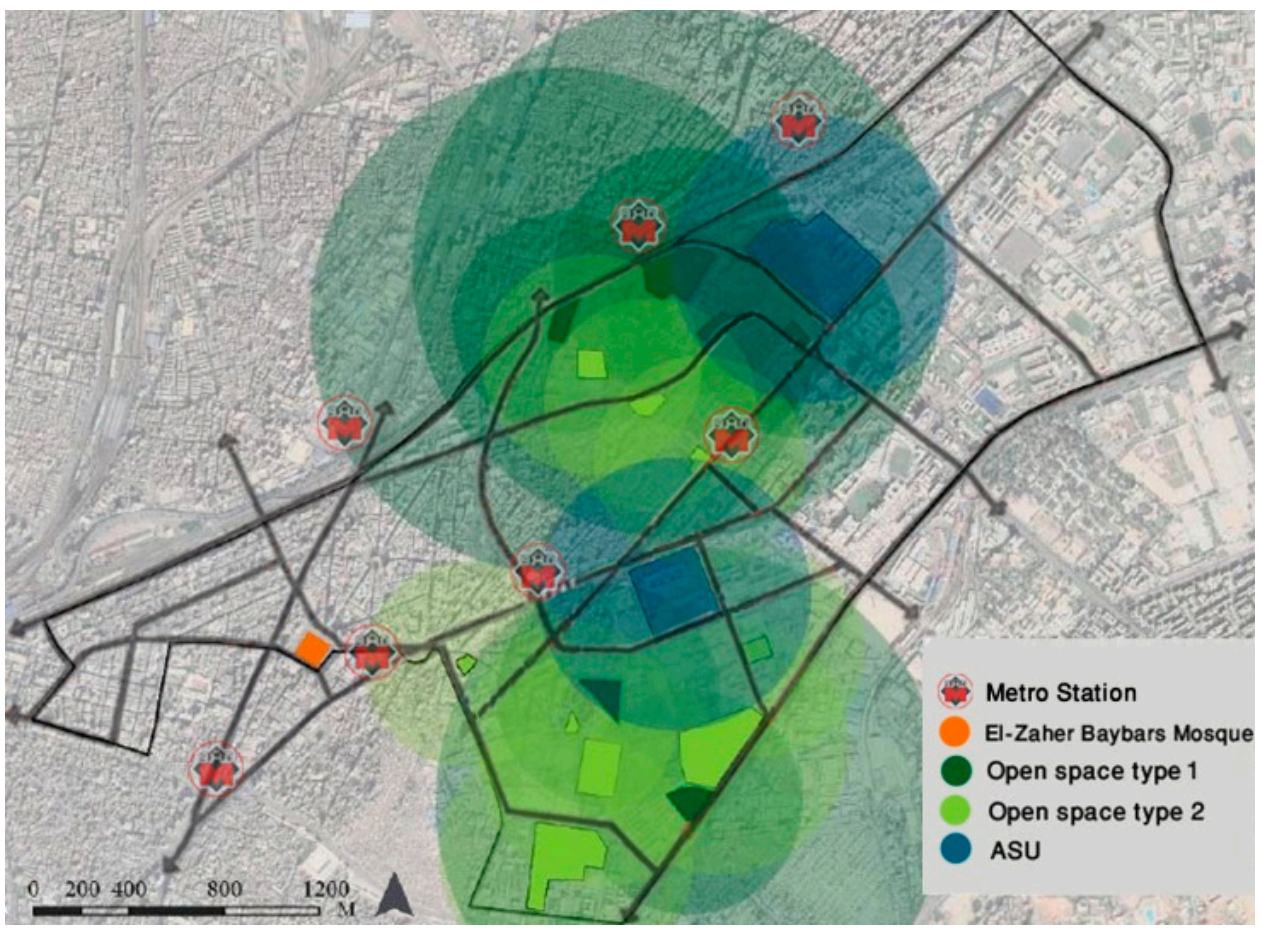

Figure 10. Analysis of open spaces' distribution at EWD.

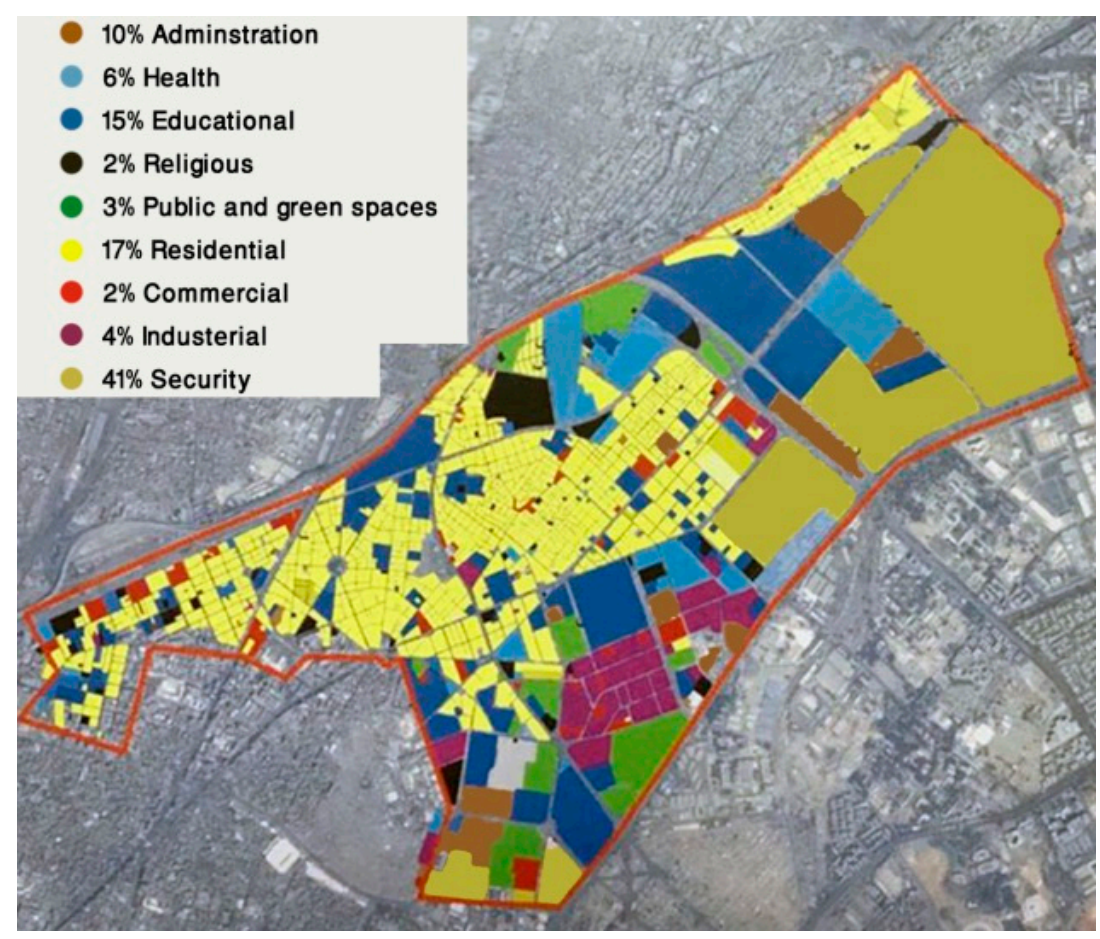

Figure 11. Land use of EWD [42]. 


\subsection{Step 2-Analysis of Opinions of Residents and Students}

\subsubsection{Analysis of Residents' Opinion}

The questionnaire was designed with four sets of questions. The first set was on general information about the respondents. In total, 71 respondents answered the questionnaire. The respondents included 63 participants from EWD (32 from El-Waily department and 31 from El-Zaher department) with 8 participants excluded as they were from other districts. Among the 63 respondents, 35 of them were female; and 38 respondents were between 22 and 40 years, which can be considered as a younger generation.

The residents' general satisfaction with the public open spaces at EWD was asked in the second set. The majority of the residents were not satisfied with the current condition of public open spaces. Among the 63 participants, 42 thought that the public open spaces at EWD were not sufficient, and 50 were generally unsatisfied with the quality. Respondents were given choices to indicate problems of public open spaces (Figure 12) - 38 selected misbehavior, followed by uncleanness with 32, and 28 for poor services. Additionally, 20 participants chose that the lighting was not enough, followed by 18 for unsecure, 16 for not enough seating, and 11 for not shaded. Moreover, 9 participants chose that public open spaces were far from their home and 6 found that they need expensive tickets to go there; 8 participants chose fenced public open spaces as a problem while 5 chose unfenced. Most incidences of dissatisfaction were related with poor maintenance. Among the "other" opinion, there was a suggestion to renovate El-Zaher Baybars mosque. There was also a view that the recent phenomenon transforming public open spaces to commercial programs was not desirable.

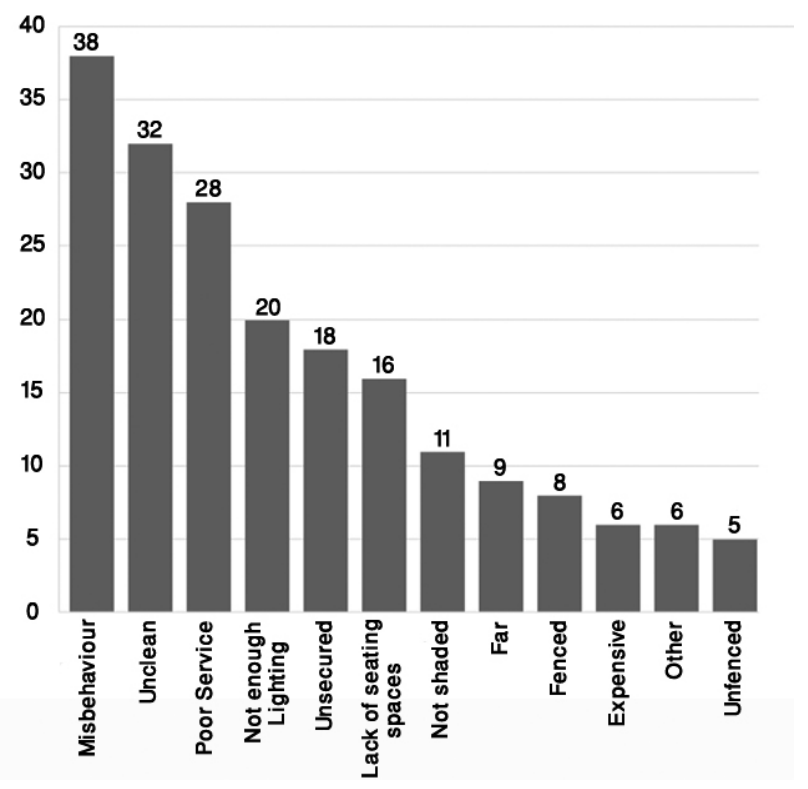

Figure 12. Public open space problems at EWD.

Residents' preference to new, open space services at EWD was asked in the third set: 37 respondents stated the need for sports areas, followed by kids and seating areas with 31 respondents; 29 participants expressed their desire for a bike lane followed by 22 for a multipurpose area. Food services came at the end of the list (Figure 13). There was no significant difference in the preference for open space programs. In terms of the edge conditions, 47 respondents preferred fenced public open spaces that allowed visual access, 5 preferred a solid fence, and 11 chose the unfenced condition. Furthermore, the result revealed that 35 respondents preferred the controlled public spaces that require membership, followed by 15 who preferred a required entrance fee; meanwhile 10 respondents chose public (free 
to enter) spaces and only 3 chose private spaces. The preference to the controlled public spaces by membership or entrance fee was 4 times higher than spaces fully opened to public.

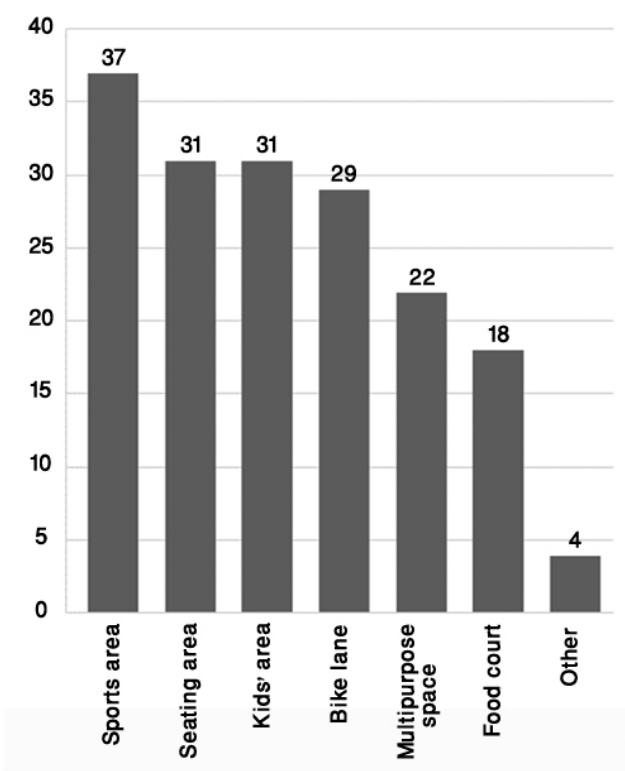

Figure 13. Residents' preference on newly opened space services to be improved at EWD.

The residents' opinion toward opening ASU as an urban public space was asked in the fourth set. This part of the survey included 13 questions. The first question addressed residents' general opinions on using the ASU main campus and the faculties of the FOE engineering campus as a public space -37 respondents refused the idea while 14 accepted and 12 were neutral. It can be said that residents generally disagreed on opening the campus as a public open space. Among all the respondents, only 15 had attended public events hosted by ASU, most of which being educational or charity events. Only 4 respondents mentioned leisure activities. Further questions were asked concerning public use of specific places in the campuses, including the historical Zaafaran Palace, green spaces, library, theater, parking area, and sports field areas. SPSS was used to calculate the weighted average of the answers to the ten questions concerning residents' views and attitudes towards accepting the ASU campus as an urban public space. Table 2 shows frequency distribution and results.

Table 2. Weighted average of residents' general acceptance on using ASU campuses as an urban public space.

\begin{tabular}{cccccccccc}
\hline & Strongly Disagree & Disagree & Neutral & Agree & Strongly Agree & Mean & SD. & Result \\
\hline ASU as a Public Space & 21 & 16 & 12 & 7 & 7 & 2.4127 & 1.35164 & Disagree \\
\hline Zaafaran & 12 & 9 & 5 & 24 & 13 & 3.2698 & 1.43916 & Neutral \\
\hline Green Spaces & 12 & 10 & 10 & 20 & 11 & 3.1270 & 1.39691 & Neutral \\
\hline Library & 4 & 3 & 9 & 32 & 15 & 3.8095 & 1.06039 & Agree \\
\hline Theater & 5 & 4 & 12 & 33 & 9 & 3.5873 & 1.07215 & Agree \\
\hline Parking & 12 & 12 & 7 & 27 & 5 & 3.0159 & 1.31360 & Neutral \\
\hline Sports Fields & 8 & 4 & 7 & 32 & 12 & 3.5714 & 1.24063 & Agree \\
\hline Open all the Time & 16 & 26 & 12 & 7 & 2 & 2.2540 & 1.06208 & Disagree \\
\hline Open for Holidays & 16 & 11 & 15 & 15 & 6 & 2.7460 & 1.33160 & Neutral \\
\hline Unfenced & 29 & 22 & 4 & 7 & 1 & 1.8730 & 1.05482 & Disagree \\
\hline General Acceptance & & & & & 2.9667 & 0.72690 & Neutral \\
\hline
\end{tabular}

Residents were asked how universities could serve surrounding communities. The result shows that 47 respondents chose workshops and seminars, followed by 35 for developing the surrounding areas, 34 for supporting charity work, and 12 for providing more public spaces. Most of the respondents 
mentioned that providing public open spaces for leisure and entertainment is not a university priority but a local authority concern. However, they believe that the university could serve the community and open its spaces for public use mostly for education-related events such as workshops and seminars (Figure 14). The last question was related with the problems that may happen in a case where the campus was opened to the public. Majority of the respondents (52) chose "misbehavior of the new users" as an expected problem, followed by 47 respondents selecting "disturbing of lectures". At the end of the questionnaire, 1 respondent added that his university, the Arab Academy for Science, Technology \& Maritime Transport (AASTMT), was previously opened for the public, which resulted in conflicts between students and residents. Another respondent highlighted the need to develop the surrounding areas, opening more public parks and providing additional parking areas. (see Figure 15)

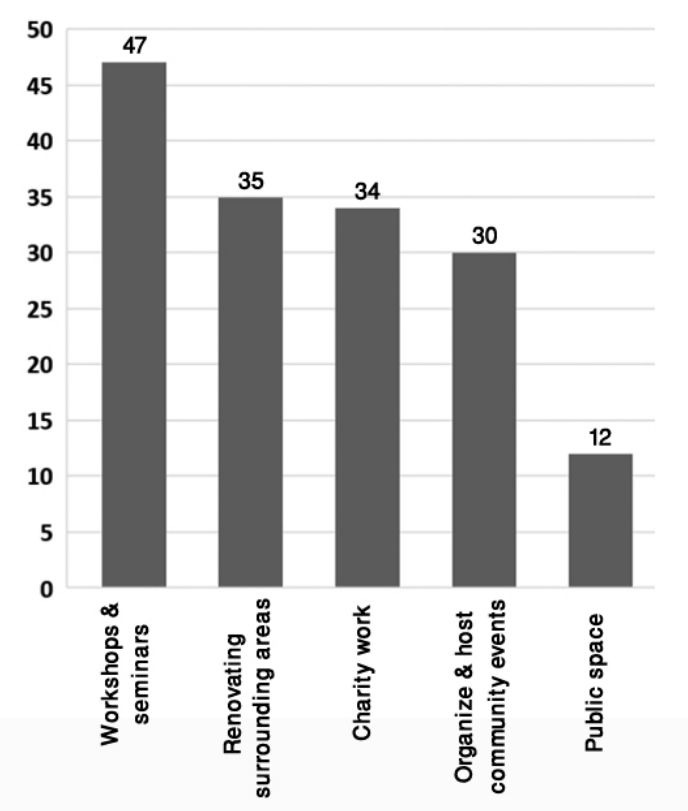

Figure 14. Residents' preferences to how the university could serve the community.

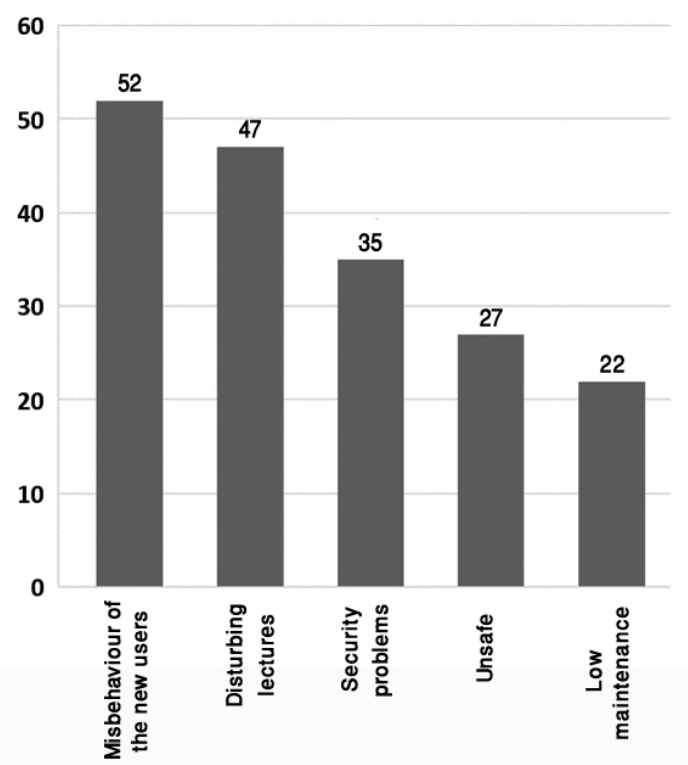

Figure 15. Residents' opinions regarding problems of opening the campus to the public. 


\subsubsection{Analysis of Students' Opinions}

The first set gathered general information about the respondents, with 82 answered the questionnaire. Respondents included 49 participants from ASU, the main campus (Faculty of Arts (27), Faculty of Law (16), Faculty of Computer and Information Sciences (4), and Faculty of Science (2)), 24 participants from the Faculty of the Engineering Campus, and 8 participants from other ASU campuses. As 1 participant, who was not a student or alumni of ASU, was excluded, responses from a total of 81 respondents were analyzed. Among the 81 respondents, 52 respondents were female. Participants included 55 undergraduates, 15 alumni, 10 master students, and 1 PhD student; 3 of them were living at EWD.

The level of general satisfaction towards open spaces in ASU campuses was asked in the second set. In general, among the 81 participants, 39 were between satisfied and very satisfied, 22 were neutral, 13 were not satisfied, and 7 were not satisfied at all. A Chi-squared test was performed using R Studio to examine the association between the levels of satisfaction and the selected campuses (Table 3). There is a statistically significant association between students' level of satisfaction and the selected campuses-79\% of respondents from FOE stated their satisfaction while only $38.7 \%$ of respondents from ASU main campus stated their satisfaction with the open spaces within their campus (Figure 16). Respondents from other ASU campuses gave their opinion on the main campus as visiting users.

Table 3. Chi-squared test result.

\begin{tabular}{cccc}
\hline $\mathbf{n}$ & Pearson $\mathbf{x}^{2}$-Test & Df & $p$-Value \\
\hline 81 & 27.053 & 8 & 0.0006923 \\
\hline
\end{tabular}

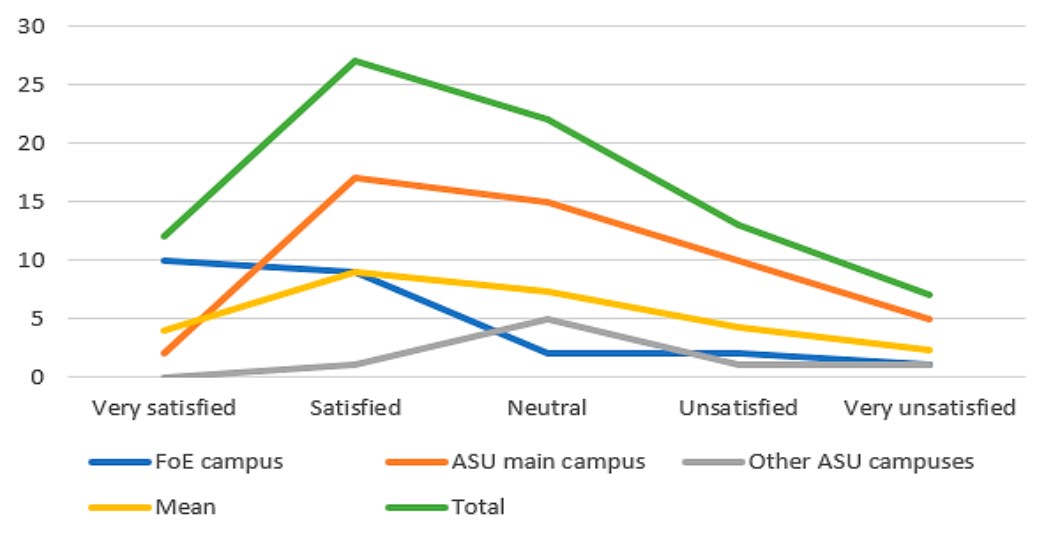

Figure 16. Chart plot shows tendency for satisfaction with the open spaces at the selected campuses.

Students' preferences to new, open space services to be improved in their campus was asked in the third set: 51 respondents stated needs for shaded areas, 36 for seating areas, and 27 for disabled-friendly facilities. Food services and greenery came at the end of the list. The result showed that there was high demand on resting spaces on the campus compared with other programs. From FOE, one respondent added the need to access comfortable seats and to focus on quality rather than quantity. From the main campus, one respondent asked to stop cutting trees and another asked to increase security control (Figure 17).

For the campus edge condition, 52 respondents preferred a fence with visual accessibility, while 24 preferred a solid fence. One undergraduate student from the FOE mentioned the need for a solid fence for privacy and separation from the traffic. Only 5 respondents preferred an unfenced campus. In terms of community-related activity participation, 71 respondents had not participated in any community serving activity associated with their university, while the other 10 respondents mentioned that their participation varied among student activity, developing targeted 
places, or charity actions. Students' opinions on opening ASU as a public space were asked in the fourth set. This part of the survey included 13 questions, the same as in the residents' questionnaire. The first question addresses students' general opinions on using the ASU and FOE campuses as public spaces -59 respondents $(73 \%)$, refused the idea. They regarded the university campus as a private space which ASU students and faculty members should use exclusively. Among all the respondents, only 13 attended public events at ASU, which were mostly cultural or educational events, opened to non-students. Similar to the residents' questionnaire, further questions were asked concerning specific places at the selected campuses to be opened to the public. Two respondents suggested opening the Zaafaran Palace to visitors. SPSS was used to calculate the weighted average of the answers to ten questions concerning students' views and attitudes towards accepting the university campus as a public space. Table 4 shows the frequency and results.

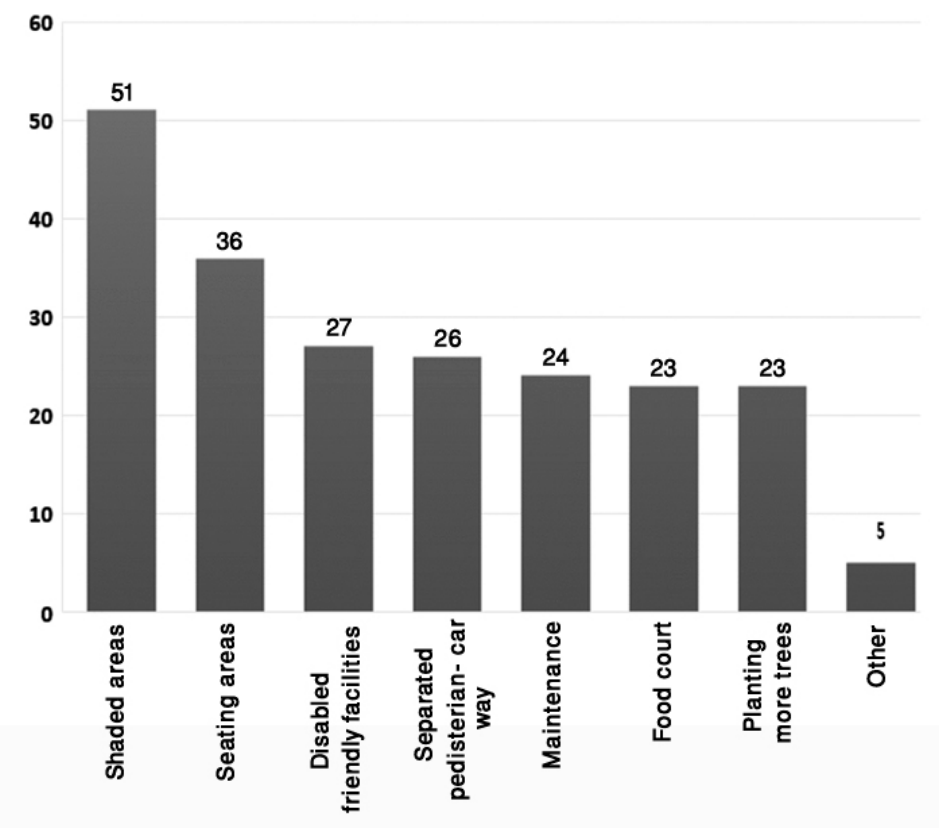

Figure 17. Students' preferences on new, open space services to be improved.

Table 4. Weighted average of students' general acceptance on using ASU campuses as an urban public space.

\begin{tabular}{ccccccccc}
\hline & Strongly Disagree & Disagree & Neutral & Agree & Strongly Agree & Mean & SD. & Result \\
\hline ASU as a Public Space & 36 & 23 & 14 & 6 & 2 & 1.9506 & 1.07123 & Disagree \\
\hline Zaafaran & 25 & 6 & 12 & 26 & 12 & 2.9259 & 1.49815 & Neutral \\
\hline Green Spaces & 26 & 14 & 18 & 15 & 8 & 2.5679 & 1.36874 & Disagree \\
\hline Library & 15 & 4 & 15 & 28 & 19 & 3.3951 & 1.39355 & Neutral \\
\hline Theater & 5 & 5 & 24 & 35 & 12 & 3.5432 & 1.02530 & Agree \\
\hline Parking & 25 & 16 & 19 & 18 & 3 & 2.4815 & 1.24611 & Disagree \\
\hline Sports Fields & 16 & 9 & 12 & 34 & 10 & 3.1605 & 1.34589 & Neutral \\
\hline Open all the Time & 23 & 14 & 24 & 15 & 5 & 2.5679 & 1.10428 & Disagree \\
\hline Open for Holidays & 12 & 13 & 28 & 25 & 3 & 2.9259 & 1.05292 & Neutral \\
\hline Unfenced & 28 & 32 & 11 & 8 & 2 & 2.0617 & 0.83109 & Disagree \\
\hline General Acceptance & & & & & & 2.7580 & 0.83109 & Neutral \\
\hline
\end{tabular}

The result shows that 55 students selected workshops and seminars followed by 44 for charity work, regarding how universities could serve their surrounding communities (Figure 18). The last question was about the problems that may happen in case the campus was opened to the public. Majority of the respondents (67) chose misbehavior of the new users, followed by disturbing of lectures with 52 respondents. (see Figure 19) 


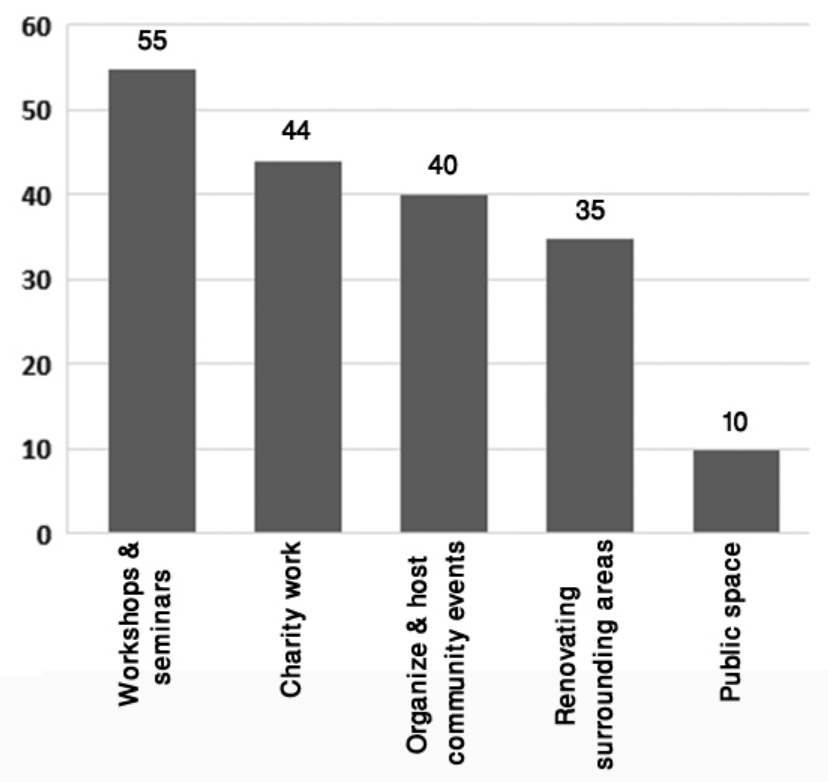

Figure 18. Students' preferences as how the university could serve the community.

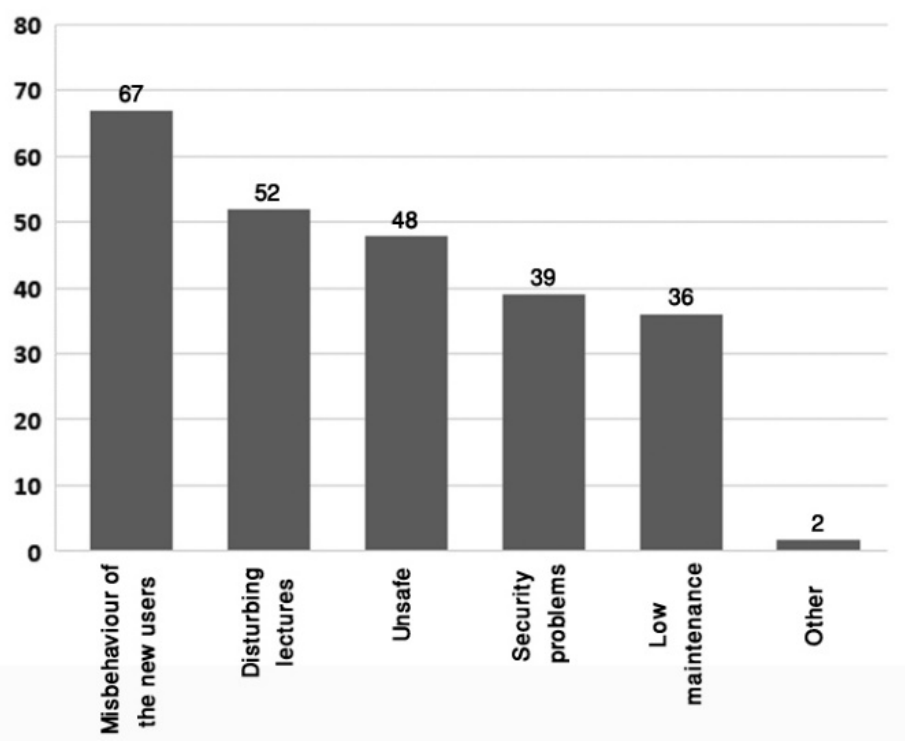

Figure 19. Students' opinions as regards problems of opening the campus to the public.

\subsubsection{Difference in Respondents' Opinions}

As mentioned earlier, the questionnaire was designed with four sets of questions-the last set investigated respondents' opinions on the ASU campus as a public space. The sample of 144 respondents consisted of two independent groups (residents and students). To check the difference between two groups' opinions, one-way ANOVA test was conducted. First, Cronbach's alpha value was calculated for the ten questions concerning respondents' opinions on using the ASU campus as a public space. The alpha coefficient for the ten questions equaled 0.832 , confirming that the items had relatively high internal consistency. Table 5 shows that the means for the two groups are close to each other. 
Table 5. Descriptive statistics.

\begin{tabular}{ccccccccc}
\hline & \multirow{2}{*}{ N } & \multirow{2}{*}{ Mean } & \multirow{2}{*}{ Standard Deviation } & \multirow{2}{*}{ Standard Error } & \multicolumn{2}{c}{ 95\% Confidence Interval for Mean } & \multirow{2}{*}{ Min. } & \multirow{2}{*}{ Max. } \\
& & & & & Lower Bound & Upper Bound & & \\
\hline Residents & 63 & 2.9667 & 0.72690 & 0.09158 & 2.7836 & 3.1497 & 1.10 & 4.40 \\
\hline Students & 81 & 2.7580 & 0.83109 & 0.09234 & 2.5743 & 2.9418 & 1.00 & 4.40 \\
\hline Total & 144 & 2.8493 & 0.79139 & 0.06595 & 2.7189 & 2.9797 & 1.00 & 4.40 \\
\hline
\end{tabular}

Levene's test was conducted to check the homogeneity of variances. Levene's statistic equals 2.806 with significance equaling 0.96 , meaning that the homogeneity of variance has been satisfied, and the variance between the two groups are equal. Furthermore, ANOVA test was conducted. Given that the $p$-value equals 0.117 , there is no statistically significant difference between residents' and students' opinions. Thus, the null hypothesis can be accepted (Table 6).

Table 6. One-way ANOVA test.

\begin{tabular}{cccccc}
\hline & Sum of Squares & df & Mean Square & F & Sig. \\
\hline Between Groups & 1.543 & 1 & 1.543 & 2.489 & 0.117 \\
\hline Within Groups & 88.017 & 142 & 0.620 & & \\
\hline Total & 89.560 & 143 & & & \\
\hline
\end{tabular}

\subsection{Step 3-In-Depth Interview}

Through the in-depth interviews, the study tries to examine three issues associated with opening a campus to the public, which cannot be examined by the survey. The three issues are as follows: (1) general perceptions of the public spaces in GC; (2) the relationship between the university and communities; and (3) challenges of considering a university campus as a public space. Interviews target the professionals, academia, local authority, and researchers.

First, in terms of the perception of the public spaces in GC, all the interviewees agreed that GC was suffering from under-supply of public spaces. Professors at the Housing and Building National Research Center (HBRC) were interviewed. The first interviewee mentioned the problem of limited budget for public spaces. She said that "providing adequate housing is more critical than the provision of adequate public spaces." The second interviewee said that as some public spaces provided by the municipality even failed to meet the minimum requirements, citizens had bad perception of public spaces in general. The professor of the Architecture Department criticized the tendency of copying the planning model of foreign cases which was not appropriate for Cairo's culture and climate. He added, "public space doesn't have to be unfenced to act perfectly [ ... ] fences are used for defining property ownership and achieving security control."

The second issue is about the relationship between the university and communities. One higher official of ASU libraries and professors from the Department of Engineering Management and the Department of Urban Design and Planning were interviewed. Interviewees mentioned the mural project at El-Abaseya square area as a good case of collaboration between ASU and EWD. One interviewee referred to the Ain-Shams university-neighborhood initiative started in 2013, which aimed to develop the areas adjacent to ASU and provide services to surrounding communities. Another interviewee said that FOE was working with local NGOs, and urban planning institutions launched projects to improve informal settlements with international funding. The official mentioned that the Cairo government and FOE started the collaborative project to connect the main and second campuses of ASU, and remodel the surrounding areas.

Third, in terms of opening ASU campuses as a public space, one professor of the Architecture Department believed that the university should provide communal events in the campus; however, proper and safe environment for students should be secured at the same time. The professor said that the American University in Cairo (AUC) kept its education zone separated from the communal zone, 
with both zones gated. It was recommended to provide an interactive boundary between the two zones, which could guarantee safety while creating more interaction with better visual connection. According to the professor, the new way of dealing with these boundaries would create points of interaction rather than points of interventions. One professor of the Urban Design and Planning Department said, "the idea can be adopted in a different way, without removing the fence and formal gate. FOE and ASU have already opened their sports fields for public use with a symbolic charge." Regarding ASU libraries, the official of ASU libraries said that, "according to the rules of procedure for university libraries, university libraries are used for higher educational purposes, not as a public library." However, the professor was working on introducing community activities to the library controlled by memberships or tickets. The professor added that the library and all main campus facilities were controlled by CCTV. One professor of the Department of Engineering Management mentioned that in the case of ASU opening their campus as a public space, "the local authority may support the university by providing contractors, technicians, and materials needed to renovate their spaces and buildings." All the interviewees believed that providing public spaces to the city and the district was not a university's prime concern although the municipality should be more responsible.

\section{Discussion}

\subsection{Current Perception and Status of Public Spaces in GC}

According to the surveys and interviews, citizens and experts both had a negative perception of the public space service in GC. Scarcity, maldistribution, insufficient supply, low budget, and inequality among social groups resulted in creating more fenced and paid privatized open spaces. In EWD, a majority of public open spaces are concentrated at the southern and northern parts; while the western part of El-Zaher department and the northeastern part of El-Waily department, where dense residential areas are located, are deficient of green and public spaces (Figure 11). The financial cost and land scarcity remain as the main obstacles in creating new, public open spaces and amenities in dense urban areas.

When the El-Zaher Baybars mosque was well-maintained, its garden functioned as a public open space; however, the mosque could not provide such public services anymore due to deterioration and improper maintenance [43]. Renovating the mosque to make it function as a public open space while preserving the building's historical values can be one of the solutions for insufficient public spaces at the western part of the district. Opening the selected university campuses as public spaces without excluding any social group could significantly improve the public space service level of the district, especially improving proximity to public spaces within $400 \mathrm{~m}$. However, the western district, where the campuses are not located, still lacks public spaces. Through investigating residents' opinions, major issues on public spaces at EWD can be summarized as follows: (1) insufficient supply and maldistribution of public spaces; (2) low public satisfaction of quality of public spaces; (3) misbehavior and uncleanness in public open spaces without membership or entrance fee; (4) high preference to semi-public open spaces requiring membership to use. A majority of the citizens regard semi-public open spaces as important urban assets that directly serve a large percentage of the public and indirectly benefit urban environment both ecologically and aesthetically; (5) privatized gated public open spaces opened to a specific group with entrance fees are widely accepted by citizens seeking quality services; and (6) high preference to gated public open spaces with visual accesses.

\subsection{University Campus as a Public Space}

\subsubsection{Opening the Campus to the Public}

Both residents and students generally disagreed on the idea of opening the campus to the public as a public space. Even though the agreement frequency of residents was higher than that of students, there was no difference in both groups statistically. There was common apprehension 
about a university's limited budget, and high population density, as the lack of public open spaces in the district would lead to overusing the campus if it is opened as a public space, resulting in chaos, misuse, low maintenance, and deterioration of facilities, in addition to the conflicts that may occur between students and residents. This result contradicts most of the recent researches about the campus planning or the campus-community partnership, encouraging the integration of the campus and the city. In order to explain the different attitudes of Cairenes, the different cultural and urban context of GC should be understood.

Due to poor public open spaces' quality in GC, most of the Cairenes regard controlled open spaces with a membership or an appropriate entrance fee, even though it is well understood that those semi-public spaces or privatized public spaces would worsen the social inequality in public services. The security control is a much more important issue for spatial planning in Cairo than in the context of the western cities. It is not a rare case to install anti-terrorism checkpoints or installations in commercial malls or government buildings. Getting rid of gates and fences from the campus is not only regarded as dangerous but also against the cultural understanding of spatial boundaries. The historical background of the main campus of ASU, which was previously the palace for the governor of Egypt influences Cairenes' perception of the university campus as an authoritative space. Different perceptions of the university in Cairo and in western cities should be also counted. In the U.S. or Europe, it is natural to consider the university as a part of the community, and campus amenities are regarded as common goods to be shared with citizens. However, Cairenes regard the university as an independent institution separated from the government or the city, even though it is a public school.

Although residents and students disagreed on the idea of making the campus as a public space in general, it cannot be concluded that they entirely rejected the idea. Both groups were neutral about opening the campus to the public in the cases of opening during holidays and weekends. There were additional suggestions from students: Opening the campus only to students including those from neighborhood-level elementary, middle, and high schools, extending its opening hours, and allowing other universities' students to use the campus.

\subsubsection{Sharing Facilities with the Public}

The results showed that there was a desire to share selected university facilities with the public in both groups of residents and students. Residents responded that theater, library, and sports fields could be shared, while students only agreed on sharing the theater. Even though students' responses to sharing the library and sports field were neutral, the frequency of agreement was much higher than disagreement. Since public libraries and cultural facilities are rarely provided by the government at the district level, residents welcomed the idea of sharing university libraries. Some students supported the idea under the condition of public use of the campus facilities controlled with strong regulations. However, in the current situation, university libraries are not eligible to be used publicly because of their limited capacity. A majority of books in the library are for higher education, and not appropriate for the general public. Both the ASU main campus and FOE campus have already opened their sports fields for middle and high school events, but not to the general public. The ideas on sharing green spaces and parking lots received a neutral response from residents. Residents partially agreed on sharing the spaces since the surrounding neighborhoods lacked parks and parking spaces. However, some of the residents were reluctant to agree on the idea since they thought university members should be primary users of the campus.

Most of the experts encouraged the idea of sharing university facilities with the public and providing more participatory programs to surrounding communities, even though they thought that the idea to operate the campus as a public space was not appropriate. There is a case of involving the Misr University for Science and Technology (MUST), one of the private universities in GC, opening its theater for public use during the weekend evenings in 2014. This policy received favorable evaluation and is continuing, to date. Taken together with the survey results and suggestions by experts, 
opening some university facilities with the right policies and regulations can be the first step to sharing the campus with the public to improve the public service quality of the district.

\subsection{University-Community Relationship}

It is important to understand that the new planning trends integrating campuses with the surrounding urban fabric appeared recently in the U.S and Europe, and was only possible with the innovation in the governance structure and healthy university-community partnerships. The physical planning strategies without supporting programs or appropriate institutional strategies easily fail. According to the survey results and interviews, there have been no active discussions between the university and the local government about sharing campus amenities with surrounding communities. The public is rarely invited to both campuses except for limited educational or cultural events. However, according to one of the interviewees, the local government and surrounding communities have the will to participate in the process renovating the ASU campus. It was also told that the university and the city recently built a partnership to prepare the strategic development plan of GC including the areas around the ASU campuses. Another interviewee mentioned that ASU libraries are preparing to open public programs for the communities. Even though ASU is not considering opening the campuses to the public, the university is preparing several programs to build healthier relationships with surrounding communities.

During the survey, many students were positive about becoming involved in participatory programs with local residents and supported the university becoming more active in community engagement. Forming a friendly relationship with the community can be a good start to building a more constructive university-community partnership. This can eventually lead the university to share more physical spaces or facilities with the public.

\section{Conclusions}

The role of the open space in the dense metropolitan area becomes increasingly important to facing urgent problems of our society, such as climate change, social inequality, and public health. However, for many developing countries suffering from rapid population growth, land scarcity, and insufficient public resources, the grand visions and goals towards a sustainable society have remained a rosy blueprint, impossible to achieve. The situation of Greater Cairo, the largest metropolitan city in the Middle East, is not much different from the metropolitan areas of other developing countries. The green space area per capita of GC is $3 \mathrm{~m}^{2}$, which is only one-third of the WHO's standard. It is hard to expect green areas of GC to increase dramatically in the near future. GC does not only suffer from quantitative scarcity of open spaces but also from poor quality. Controversially, privatization of the green and public space has solved a part of the problem for the middle-class. However, those privatized open spaces increase inequality in the public service of GC.

Recently, many researchers have shown a special interest in the campus planning projects integrating the campus with the city. This approach provides an opportunity to form a more cooperative university-community partnership as well as more open space amenities to the city without spending public funds. This research explored the potential of this recent trend in campus planning to be the alternative solution for the open spaces' scarcity problem of GC. In order to find out whether the university campus can work as a public space or not in the Cairene context, ASU campuses in EWD were selected as study sites.

The spatial analysis, the first step of the research, showed that the open space ratio of EWD and its accessibility to open spaces from major residential areas would be improved greatly if ASU campuses are opened to the public and counted as public spaces in theory. For the second step, the research asked the opinions of residents and students about sharing the campus with communities. Unlike the results of preceding studies, both residents and students opposed the idea of opening the campus to the public in general. This result implies that the policy or strategies proved to be successful in the specific context can fail if different cultures and regional characteristics are not carefully considered. 
Even though respondents think it is not appropriate to regard the campus as a public space, there is a certain level of agreement on sharing selected facilities, such as the theater, libraries, and sports fields with the public. The third step of the research, the in-depth interviews with experts, mainly the members of the university, was designed to find out other possibilities for the university to contribute to the city and the adjacent communities. Experts agreed on partially opening the campus to the public with sharing selected university facilities. They also emphasized building more constructive university-community partnerships.

To answer the main research question, regarding whether ASU can work as a public space or not, it is not appropriate to open the ASU campuses as public spaces right away, but the campuses can contribute to improving the problems of poor public service and scarcity of open spaces at the district level with step-by-step preparation and implementation of policies in the long term. Converting a gated campus to a public space requires gradual transformation and ongoing communication between the university and surrounding communities. The implantation process could follow the reverse direction of the research steps. The first step for opening the campus to the public is to form good university-community partnerships. The university needs to educate the public to use the campus amenities properly and help the community to take more responsibility in managing the shared resources. The community needs to understand and respect the university's policies and try to regard the university as a member of the community. The next step is sharing selected university facilities with the community. It can start with sharing a university's sports facilities with community schools since the ASU main campus and the FOE campus have already been implementing such a policy. The university can increase opening facilities gradually with appropriate guidelines and regulations. Fully opening the campuses to the public, like Western countries, may not be either possible or appropriate in the context of GC; however, the strategic sharing of university facilities and open spaces can have similar effects to providing more quality public spaces in the district. This suggestion is only one of the scenarios to find a solution for the urgent problems of Cairo through the partnership between the university and the community. Much more undiscovered potentials can be developed through strategic approaches to various urban issues.

Limited access to spatial data of GC was one of the major limits of the research. Due to a lack of sufficient GIS data, it was not possible to do a more advanced network analysis to find out the proximity range of public spaces within the districts. Moreover, because of time constraints, the research structured the respondents simply into two groups: residents and students. If the resident group was divided into more diverse groups according to different districts or income level groups, more detailed information about the inequality of public service could be acquired.

Author Contributions: M.A. was responsible for research design, data collection, and analysis. Y.K. contributed conceptualization, result interpretation, and editing according to review. All authors contributed to writing the paper. All authors have read and agreed to the published version of the manuscript.

Funding: This research was funded by the National Research Foundation of Korea (NRF), grant number NRF-2018R1C1B504409.

Conflicts of Interest: The authors declare no conflict of interest.

\section{References}

1. Nilsson, K.; Åkerlund, U.; Konijnendijk, C.C.; Alekseev, A.; Caspersen, O.H.; Guldager, S.; Kuznetsov, E.; Mezenko, A.; Selikhovkin, A. Implementing urban greening aid projects-The case of St. Petersburg, Russia. Urban For. Urban Green. 2007, 6, 93-101. [CrossRef]

2. United Nations. SDG Tragets and Indicators. Available online: https://sdgs.un.org/goals/goal11 (accessed on 16 August 2020).

3. Sustainable Development Solutions Network [SDGN]. Indicators and a Monitoring Framework for the Sustainable Development Goals: Launching a Data Revolution for the SDGs; United Nations: Nairobi, Kenya, 2015. 
4. United Nations Human Settlements Programme (UN-Habitat). Adequate Open Public Space in Cities. Available online: http://unstats.un.org/unsd/post-2015/activities/egm-on-indicator-framework/ docs/BackgroundnotebyUNHabitat-Proposalforapublicopenspaceindicator-EGM_Feb2015.pdf (accessed on 29 December 2018).

5. Rabbat, N. A Brief History of Green Spaces in Cairo. In Cairo: Revitalising a Historic Metropolis; Bianca, S., Jodidio, P., Eds.; Umberto Allemandi: Turin, Italy, 2004; pp. 43-53. ISBN 8842212350.

6. Kafafy, N.A. The Dynamics of Urban Green Space in an Arid City; the Case of Cairo- Egypt. Ph.D. Thesis, Cardiff University, Cardiff, Wales, UK, 2010.

7. Abu-Lughod, J. Tale of Two Cities: The Origins of Modern Cairo. Comp. Stud. Soc. Hist. 1965, 7, 429-457. [CrossRef]

8. Abdelhadi, D.S. Sustainable Urban Landscapes: A System Based Approach for Developing a Sustainable Urban Green Spaces Network Heuristic Assessment Model. Ph.D. Thesis, Cairo University, Cairo, Egypt, 2016.

9. Almatarneh, R.T. Choices and changes in the housing market and community preferences: Reasons for the emergence of gated communities in Egypt. Ain Shams Eng. J. 2013, 4, 563-583. [CrossRef]

10. United Nations Human Settlements Programme (UN-Habitat). Global Public Space Toolkit: From Global Principles to Local Policies and Practice; United Nations: Nairobi, Kenya, 2015; ISBN 978-92-1-132656-7.

11. UN-Habitat The Strategic Plan 2020-2023. 2019. Available online: https://unhabitat.org/sites/default/files/ documents/2019-09/strategic_plan_2020-2023.pdf (accessed on 10 September 2019).

12. Moore, C.W. You Have to Pay for the Public Life: Selected Essays of Charles W. Moore; Keim, K., Ed.; MIT Press: Cambridge, Massachusetts, 2001; ISBN 0-262-13373-3.

13. World Health Organization (WHO). Health Indicators of sustainable cities. In Proceedings of the The Rio+20 UN Conference on Sustainable Development, Rio de Janeiro, Brazil, 20-22 June 2012; pp. 17-18.

14. GOPP; UN-Habitat; UNDP. Greater Cairo (GC) Urban Development Strategy, Part 1: Future Vision and Strategic Direction; Gopp: Cairo, Egypt, 2012.

15. National Organization for Urban Harmony. Rules and Principles of Urban Harmony for Open and Green Areas; NOUH: Cairo, Egypt, 2010.

16. Saikia, A. Spatial Distribution of Parks- A Case of Bhopal. Available online: http://www.vasturaag.com/ spatial-distribution-of-parks-a-case-of-bhopal/ (accessed on 15 January 2020).

17. Talen, E. The spatial logic of parks. J. Urban Des. 2010, 15, 473-491. [CrossRef]

18. Gumprecht, B. The campus as a public space in the American college town. J. Hist. Geogr. 2007, 33, 72-103. [CrossRef]

19. Turner, P.V. Campus: An American Planning Tradition; MIT Press: Cambridge, MA, USA, 1984.

20. Roemmich, J.N.; Balantekin, K.N.; Beeler, J.E. Park-like campus settings and physical activity. J. Am. Coll. Heal. 2015, 63, 68-72. [CrossRef] [PubMed]

21. Haar, S. The City as Campus: Urbanism and Higher Education in Chicago; University of Minnesota Press: Minneapolis, MN, USA, 2011.

22. Sassaki University of Pennsylvania Penn Connects. Available online: https:/www.sasaki.com/projects/ university-of-pennsylvania-penn-connects/ (accessed on 16 August 2020).

23. Sassaki University of Washington Campus Master Plan. Available online: https://www.sasaki.com/ projects/university-of-washington-campus-master-plan-and-innovation-district-framework/ (accessed on 16 August 2020).

24. AECOM North West Cambridge. Available online: https://aecom.com/projects/north-west-cambridge/ (accessed on 16 August 2020).

25. Rashidi, A. University Campus as a Public Space of the City Case Study: Eastern Mediterranean University Campus. Master Thesis, Eastern Mediterranean University, Gazimağusa, North Cyprus, 2013.

26. Fassi, D.; Galluzzo, L.; Rogel, L. Hidden public spaces: When a university campus becomes a place for communities. In Proceedings of the DRS2016: Future-Focused Thinking, Brighton, UK, 27-30 June 2016; pp. 3407-3421.

27. Dalton, L.C.; Hajrasouliha, A.H.; Riggs, W.W. State of the Art in Planning for College and University Campuses: Site Planning and Beyond. J. Am. Plan. Assoc. 2018, 84, 145-161. [CrossRef]

28. Hebbert, M. The campus and the city: A design revolution explained. J. Urban Des. 2018, 883-897. [CrossRef]

29. Way, T. The urban university 's hybrid campus. J. Landsc. Archit. 2016, 11, 42-55. [CrossRef] 
30. Bringle, R.G.; Hatcher, J.A. Campus-community partnerships: The terms of engagement. J. Soc. Issues 2002, 58, 503-516. [CrossRef]

31. Martin, L.L.; Smith, H.; Phillips, W. Bridging "Town \& Gown" through innovative university-community partnerships. Innov. J. Public Sect. Innov. J. 2005, 10, 1-16.

32. Bruning, S.D.; McGrew, S.; Cooper, M. Town-gown relationships: Exploring university-community engagement from the perspective of community members. Public Relat. Rev. 2006, 32, 125-130. [CrossRef]

33. McHugh, K.A.; Meister, R.J. Campus-Public Partnerships: Successful Models for Strategic and Facilities Planning. Mag. High. Learn. 2004, 36, 22-31. [CrossRef]

34. Porter, M.E. Colleges and Universities and Regional Economic Development: A Strategic Perspective. Available online: https://www.hbs.edu/faculty/Pages/item.aspx?num=46840 (accessed on 18 August 2020).

35. Heynen, N.; Perkins, H.A.; Roy, P. The Political Ecology of Uneven Urban Green Space. Urban Aff. Rev. 2006, 42, 3-25. [CrossRef]

36. Combera, A.; Brunsdona, C.; Green, E. Using a GIS-based network analysis to determine urban greenspace accessibility for different ethnic and religious groups. Landsc. Urban Plan. 2008, 86, 103-114. [CrossRef]

37. Sister, C.; Wolch, J.; Wilson, J. Got green? addressing environmental justice in park provision. GeoJournal 2010, 75, 229-248. [CrossRef]

38. Reyesa, M.; Páeza, A.; Morency, C. Walking accessibility to urban parks by children: A case study of Montreal. Landsc. Urban Plan. 2014, 125, 38-47. [CrossRef]

39. General Organization for Physical Planning (GOPP) Geographical Maps. Available online: http://gopp.gov. eg/eg-map/ (accessed on 16 August 2020).

40. Google Maps Ain-Shams University. Available online: https://www.google.com/ (accessed on 2 October 2018).

41. Ebrahim, G.A.; Farid, A. Mainstream Programs Student Guide; Ain Shams University: Cairo, Egypt, 2017.

42. General Organization for Physical Planning (GOPP). Capital Organization Initiative_Detailed Planning of El-Waily District; GOPP: Cairo, Egypt, 2013.

43. Tadamun AL-ZAHIR. Available online: http://www.tadamun.co/?post_type=city\&p=8475\&lang=en\&lang= en\#.XpbqGVQzZdg (accessed on 31 March 2019).

(C) 2020 by the authors. Licensee MDPI, Basel, Switzerland. This article is an open access article distributed under the terms and conditions of the Creative Commons Attribution (CC BY) license (http://creativecommons.org/licenses/by/4.0/). 